\title{
Los gabinetes de prensa institucionales de los ayuntamientos españoles en internet
}

\author{
Berta GARcía Orosa \\ Universidad de Santiago de Compostela \\ bertago@gmail.com \\ Pablo VÁzQuez SANDE \\ Universidad de Santiago de Compostela \\ blinho87@gmail.com
}

Recibido: 30/07/2012

Aceptado: 11/10/2012

\begin{abstract}
Resumen
Los gabinetes de comunicación institucionales cada vez adquieren una mayor influencia en la conformación de la agenda mediática. Este crecimiento continuado fue espectacular en el ámbito de la administración local adaptándose a la realidad con nuevas fórmulas como las mancomunidades o las asesorías externas y ampliando la influencia de su mensaje a través de las herramientas que ofrece internet. Pero, ¿son realmente institucionales los gabinetes de comunicación de los ayuntamientos o responden a intereses políticos concretos? Algunos indicios en la conformación y dinámica de los departamentos así como en el mensaje transmitido, hacen sospechar que detrás de estos gabinetes no está el fin democrático de la información, sino la propaganda de un determinado partido político. La investigación propone una aproximación a la actuación de las salas de prensa institucionales on line.
\end{abstract}

Palabras clave: gabinete on line, comunicación política, información institucional, comunicación organizacional, periodismo.

\section{Local government on line press offices}

\begin{abstract}
The influence and importance of institutional press office have grown on the media agenda making increasingly. On local governments this growth is so weighty that net tools or new ways such as communities or external consultants are been engaged in order to expand their message. Nevertheless, are local government press offices genuinely institutional or just a replication of specific political party interests? Some traces on the conformation and dynamics of these departments, as well as on the transmitted message, lead us to suspect that the reason of these offices is not the democratic purpose of the information but political propaganda. Present research proposes a insightful approach to the local government on line press office performance.

Keywords: on line press office, political communication, institutional information, organizational comunication, journalism.

\section{Referencia normalizada}

GARCÍA OROSA, Berta y VÁZQUEZ SANDE, Pablo (2012): "Los gabinetes de prensa institucionales de los ayuntamientos españoles en internet". Estudios sobre el mensaje periodístico. Vol. 18, núm. especial octubre, págs.: 405-412. Madrid, Servicio de Publicaciones de la Universidad Complutense.
\end{abstract}

Sumario: 1. Introducción. 2. Metodología. 3. Desarrollo. 4. Conclusiones. 5. Referencias bibliográficas.

\section{Introducción}

La comunicación institucional en la administración local constituye uno de los sectores emergentes con mayor crecimiento cuantitativo en las últimas décadas dentro del despegue generalizado de la comunicación organizacional en España. Con tendencias similares a las de otros ámbitos, los ayuntamientos se dotaron de departamentos institucionales encargados de su comunicación con los ciudadanos, incluso experimentando 
nuevas fórmulas que permitiesen superar las limitaciones presupuestarias de la administración local como las mancomunidades comunicativas. Con los medios de comunicación como público principal y con internet y las social media como uno de los principales avances (Dircom, 2012, 2012: 12-24) se formó en los últimos años una red de gabinetes institucionales de comunicación con gran influencia en la opinión pública.

Estos departamentos municipales son uno de los pilares básicos de la transparencia y la comunicación democrática con los ciudadanos pero, a la vez, en ellos confluyen actores y poderes con intereses diferenciados y a veces contrapuestos que pueden dificultar su tarea. Dentro de la comunicación del ayuntamiento pueden coincidir en el mismo departamento personas y fines de la institución como garante de la participación de los ciudadanos y del juego democrático y de los partidos políticos como entidades de carácter difuso, situados en la frontera entre lo público y lo privado (Bartolomé, 2012: 285).

La investigación y el informe que se presenta a continuación nacen de la preocupación de la peligrosa mezcla para la democracia de los dos ámbitos y pretende ser una radiografía de la actividad de los gabinetes de comunicación institucionales de la administración local a través de uno de los instrumentos de comunicación con mayor desarrollo en los últimos años, las salas de prensa on line.

\section{Metodología}

El estudio, de carácter exploratorio, realiza una primera aproximación a la actuación de las salas de prensa en la esfera de la administración local en la red y parte de la hipótesis de que la mayoría de estos departamentos mezclan tareas de comunicación institucional con las propias de partido, con la consiguiente confusión de las bases de la transparencia democrática y de información como servicio público.

En la investigación se analizaron las salas de prensa institucionales en red de los ayuntamientos españoles con más de 50.000 habitantes $^{1}$ entendiendo por sala de prensa on line los departamentos de comunicación institucionales de la administración local que realicen comunicación con sus públicos on line y off line. Por lo tanto, tendría que ser una comunicación que responda a los intereses de los ciudadanos del municipio y no a los particulares de entidades del segundo o tercer sector. Asumimos para el desarrollo del estudio la clasificación clásica de los sectores, aun siendo conscientes de las limitaciones y prejuicios ideológicos que implica pero considerando que su funcionalidad desde el punto de vista analítico continúa siendo válida. En el siguiente cuadro se puede observar un resumen de las principales características de cada sector:

Con el fin de comprobar la tendencia de las salas de prensa municipales se analizan dos grandes ámbitos: la estructura del gabinete y la dinámica del mismo a través de dos métodos de investigación. El primero, un análisis de contenido cuantitativo, en el que se trabajaron tres grandes dimensiones: a) datos generales del ayuntamiento; b) características específicas de la sala de prensa y c) los documentos transmitidos en la sala de prensa institucional.

Se estudiaron los departamentos de los 145 ayuntamientos de más de 50.000 habitantes si bien de este total hay que detraer cinco casos por problemas informáticos

${ }^{1}$ Fuente: Ine, 2011 y los facilitados por el Ministerio de Presidencia en julio de 2012. 
derivados de la administración municipal en cuestión ${ }^{2}$, con lo que el corpus que manejamos en esta fase es de 140 casos. El seguimiento de la información publicada se realizó entre los días 23 y 29 de julio de 2012 con un total de 1.268 documentos.

Del mismo modo, con el fin de conocer la actividad en la web de los grupos municipales y poder observar si la ausencia o escasez de información sobre los de la oposición en la web municipal respondía a un interés de partido o simplemente a la falta de actividad de estos grupos, se analizaron también los grupos municipales de la oposición de las poblaciones indicadas.

El segundo método empleado, de carácter cualitativo con el fin de completar e interpretar la información recibida a través del análisis de contenido, fue una encuesta semi-estructurada con los responsables de los gabinetes de comunicación de los diferentes departamentos de los ayuntamientos de poblaciones de más de 50.000 habitantes realizada en 2012 en los que se trabajaron los siguientes ítems distribuidos en un total de 20 preguntas:

1. El nivel de estudios, la formación académica general y la formación específica de los trabajadores de los gabinetes.

2. La importancia del peso específico que se otorga a la comunicación entre los puestos de confianza y laborales eventuales.

3. La percepción sobre la existencia de casos de simultaneidad de tareas institucionales y partidistas.

4. La participación de los periodistas del gabinete institucional en actividades de partido como las campañas electorales.

5. La situación contractual.

A continuación se presenta un resumen de los principales elementos de análisis y conclusiones.

\section{Desarrollo}

La esencia de la administración pública es la de ser un aparato organizativo a las órdenes el gobierno dispuesto para la satisfacción de los intereses públicos, que son definidos por las normas jurídicas que debe cumplir con absoluta neutralidad u objetividad, con eficacia y sumisión al Derecho (artículo 103 de la Constitución española) y, por lo tanto, estos son los principios a los que debería estar sometida u orientada la comunicación.

Al gobierno, de este modo, se le reconoce la capacidad de liderato político poniendo bajo su inmediata dirección la administración pública, que aparece como el aparato organizativo substancial del Estado (Cosculluela, 1993). La administración pública se caracteriza por la continuidad y permanencia ya que los fines que le están encomendados exigen una actividad continua y permanente con absoluta independencia de las eventuales situaciones de cambio o crisis política que pueda afectar al

2 Las salas de prensa excluidas son las de Dos Hermanas, Estepona, Huesca y Valencia por errores informáticos ajenos al equipo investigador y la de Burgos por no encontrar ningún espacio específico consignado a las relaciones informativas en ninguno de los apartados de la web institucional. 
poder ejecutivo. Continuidad y neutralidad, por lo tanto, serían dos elementos fundamentales de la comunicación del gobierno local necesaria para la permanencia de sus líneas estructurales esenciales, de composición profesional y burocrática. En las próximas líneas analizaremos brevemente la situación de estas características básicas en la comunicación institucional de la administración local en dos ejes: la estructura y la dinámica de las salas de prensa on line.

Desde el punto de vista estructural la mayoría de los analizados son gabinetes de prensa institucionales ubicados dentro de la administración pública (el 56,3\% son institucionales mientras que solo el $2,8 \%$ pertenecen al tercer sector) e, incluso, en algunos casos el gabinete institucional es el responsable también de la comunicación del partido que formó gobierno ya que en el $21,1 \%$ de los ayuntamientos analizados hay un gabinete institucional y uno por cada grupo municipal de la oposición pero ninguno para el grupo municipal en el gobierno. De este modo, se asume que la información sobre el partido del gobierno la realizará directamente el institucional confundiendo desde el inicio las dos funciones.

$\mathrm{Al}$ descender un nivel y acudir a los recursos humanos observamos que solo el $19,7 \%$ asegura tener personal en el grupo municipal de los partidos en el gobierno para canalizar la comunicación de ese ámbito y así separarlo del terreno institucional. Se suele romper en estos casos el principio de permanencia ya que la mayoría de los trabajadores tienen contratos eventuales (el 66,2\% de los encuestados tienen un contrato de confianza) provocando un sentimiento de "provisionalidad" que manifiestan tener muchos de los directores de comunicación que no les ayuda a afrontar nuevos retos de alcance "menos político" y de desarrollo o consolidación de la institución. Además, el 43,7\% del total manifiesta haber participado profesionalmente en las últimas elecciones municipales del 22 de mayo de 2011 y el 46,5\% confiesa que sintió que su puesto de trabajo dependía de lo ocurrido en esa cita democrática. Pese a que más del $60,6 \%$ considera que simultanear la tarea de partido con la de la institución no es ético, un $63,4 \%$ afirma conocer casos de este tipo.

En cuanto a la dinámica de trabajo y los documentos proporcionados son propios de otros sectores ya que, si bien el gabinete institucional debería responder a los intereses de los ciudadanos y transmitir información sobre la actividad de toda la corporación, muchas veces se convierten en altavoces de la actividad del gobierno únicamente y, en algunos casos, incluso solo del alcalde. El promotor suele ser exclusivamente el gobierno local (en el $69 \%$ de los casos) y sólo en un $2,6 \%$ están propuestos exclusivamente por los grupos de la oposición. Así, observamos que en 53 ayuntamientos (un $45,7 \%$ del total) se prioriza y se centra la atención, desde el titular, en la presencia del alcalde. A modo de ejemplo, podemos mencionar el caso de El Puerto de Santa María, donde la noticia no es la descripción de los presupuestos sino que El alcalde entrega la documentación de los Presupuestos de 2012 en formato digital. Una información habitual, que se repite en varios municipios (como Albacete) son las visitas a los campamentos urbanos, donde el enfoque no es que se estén realizando estas actividades sino que el regidor se desplaza a ellas. Por lo tanto, asistimos a un problema de enfoque temático con informaciones que priorizan al actor sobre el propio acontecimiento. 
En cinco ayuntamientos al menos la mitad de las informaciones transmitidas giran en torno al alcalde y la presencia del regidor se convierte en el titular de la nota de prensa. Se trata de Albacete (el 71,4\% de todas sus informaciones cumplen estas características), Ciudad Real (63,6\%), Torremolinos (62,3\%), Fuenlabrada (50\%) y Toledo $(50 \%)$. Parece clara, entonces, la tendencia a la sobreexposición del alcalde, un estudio que podría complementarse con el análisis de la utilización de imágenes y de quiénes aparecen en ellas, como en Vigo, donde el regidor está presente en el 35,3\% de las fotografías que acompañan a la nota de prensa.

En segundo lugar, constatamos que en 10 municipios (un 8,6\% del total) se emplean medios públicos al servicio de la institución para aludir a asuntos que o no son de competencia municipal o la capacidad de injerencia de la institución en ellos es nula. En algún caso, se trata de comunicados específicos de rechazo a medidas tomadas por administraciones de otro color político: en Avilés leemos el siguiente titular Concejala de Igualdad: "con la propuesta del PP nos ponemos a la cola de Europa" (en referencia a la ley del aborto, como se complementa en otros elementos de la cabeza de titulación); en Fuenlabrada nos encontramos que El alcalde acusa a la Comunidad de Madrid de deslealtad institucional al derivar a los dependientes a los ayuntamientos (en el texto se mencionan situaciones de necesidad creadas por los recortes del gobierno y un afán de desactivar el estado del bienestar); en Lugo en la cabeza de titulación se nos dice que la concejala de Economía agradece el trabajo de los funcionarios en un momento en el que son víctimas del acoso y de los recortes del PP; en Rubí uno de los titulares dice que Más de 1.300 personas verán reducida su prestación económica a consecuencia de la reforma de la Ley de Dependencia; en Santa Coloma de Gramenet leemos que La alcaldesa denuncia que los recortes en la Ley de la Dependencia impactan gravemente en la ciudad, que padece especialmente la crisis y en Vigo el alcalde celebra una reunión con la Federación de Peluqueros para criticar la subida del IVA.

En otros casos los enfoques son menos partidistas y no se llevan al titular sino que se introducen críticas en el cuerpo de las informaciones, como en Fuengirola (el Ayuntamiento ya inició el plan de austeridad en 2008 cuando el PSOE en el gobierno de España decía que no había crisis), Sanlúcar de Barrameda (en un comunicado sobre la reducción del IBI para familias numerosas señalan que de nuevo el PP se olvida de la mala situación económica por la que pasan muchas familias) y en Terrassa se crea una comisión sobre mujeres y crisis dado que los recortes en diferentes ámbitos (dependencia, inmigración, salud, reforma laboral, etc) afectan de manera muy especial a estos colectivos.

Además de la omnipresencia del alcalde y de contenidos ajenos a lo municipal, también se puede utilizar la sala de prensa on line al servicio de las siglas del partido del gobierno cuando se convierte en altavoz de las reclamaciones a otras administraciones de diferente color político. Así, hasta en 14 municipios (un 12,1\% del total) encontramos reivindicaciones a otras instituciones jerárquicamente superiores. Entre los municipios que recurren a esta dinámica llama la atención el de Jaén, donde en una semana se han emitido tres notas de prensa contra la Junta de Andalucía en las que se culpa a la administración autonómica de provocar despidos al dejar de financiar un 
programa, se insta a que cumpla con el pago de servicios de ayuda a domicilio de la ley de dependencia y se critica que solo haya subsanado el $15 \%$ de las deficiencias del tranvía. También Toledo se muestra muy incisivo con otros tres comunicados de este tipo y otras ciudades, como Lugo, dedican la mitad de una información institucional a reprochar al ente autonómico su política en materia de empleo. Con frecuencia, la crítica es abierta, pero en Zaragoza apuestan por fórmulas más sutiles y veladas como a la hora de presentar una concesión de ayudas a 38 proyectos culturales, cuando se apunta que al contrario que otras administraciones, creemos que la cultura es un sector productivo. Pero también es cierto que en cuatro ocasiones (Lorca, Mijas, Murcia y Sagunto) las reivindicaciones se dirigen a administraciones dirigidas por el mismo partido político al que pertenece el alcalde del municipio. Mucho más frecuente es, sin lugar a dudas, el elogio a las medidas y decisiones de los gobiernos de la misma formación explicando siempre las siglas del partido.

Una cuarta utilización partidista de las salas de prensa pasa se detecta cuando se incluyen en la web municipal comunicados emitidos por otras administraciones en los que no se produce un tratamiento específico por parte de la institución local. Aunque solo se registre en 7 casos (un 6\%), resultan llamativos ejemplos como el de Alcalá de Guadaira, donde el alcalde es presentado como senador y se anuncia su presentación de una pregunta en esta Cámara; en La Línea de la Concepción, donde una nota de prensa lleva por titular El diputado socialista González Cabaña informa a la alcaldesa que el grupo del PSOE en el Congreso de los Diputados presentará a Gibraltar una solicitud de moratoria para que continúe la actividad pesquera; o en Puertollano, cuya página local presenta el siguiente comunicado: La Diputación seguirá apoyando el programa de acogida de Saharauis (cabe matizar que el presidente de la Diputación es el secretario general del partido que gobierna la ciudad). Encontramos situaciones similares en Sanlúcar de Barrameda, Santander, Torrevieja y Vilanova i la Geltrù.

En quinto lugar nos referimos a las notas de prensa emitidas por los ayuntamientos en las que se entremezcla el contenido informativo institucional con la respuesta a las declaraciones de la oposición, algo que ocurre en ocho municipios (un 6,9\%). En algún caso, estas contestaciones limitan con la ofensa y parecen impropias del tono respetuoso que cabría esperar en una institución, como ocurre en Gandía, donde en la presentación de un balance un edil afirma que son las cifras lo que importa, no lo que diga la concejala socialista. Otros ejemplos de respuesta a la oposición en notas de prensa institucionales los encontramos en Alcalá de Guadaira, Almería, Jerez de la Frontera, Lugo, Rubí, Torrevieja y Zaragoza.

Por último, apreciamos también que se produce un interés partidista con la actitud revisionista que muestran 14 ayuntamientos (un $12,1 \%$ del total), especialmente aquellos donde hubo cambio de gobierno tras las últimas elecciones municipales. De este modo, son frecuentes los reproches al anterior ejecutivo, especialmente en los casos de A Coruña (en cinco de las ocho notas de prensa emitidas durante esa semana se resalta la necesidad de separación de etapas) o en Jaén, donde en siete comunicados se critica al gobierno local precedente. 
Constatada la tendencia en las salas de prensa institucionales a confundir en algunas ocasiones su función institucional con las tareas e intereses propios del partido político tanto desde el punto de vista estructural como de su dinámica de trabajo, consideramos necesario comprobar si la línea también era traspasada en sentido contrario, es decir, con información institucional emitida por los diferentes ayuntamientos recogida en los espacios web de los partidos políticos que ocupan la alcaldía. Para ello, hemos comprobado las notas de prensa emitidas por cada grupo municipal (y recogidas en su web) a lo largo de la misma semana (del 23 al 29 de julio de 2012) y lo hemos contrastado con las salas de prensa de cada municipio.

La tendencia es similar al caso anterior, ya que un $10,3 \%$ de los grupos políticos que ocupan alcaldías no incorporan contenidos de carácter municipal sino que se limitan a recoger mensajes y notas de prensa emitidas a nivel provincial o nacional por el partido en cuestión y, entre las que sí tienen información de carácter municipal existe una confusión importante entre partido e institución en el 58\% de los casos.

Cabe ahora preguntarse si esta politización de las instituciones es una herramienta al alcance del partido en el gobierno o bien de todos los que forman parte de la corporación. Para averiguarlo, y una vez constatada la total ausencia en las salas de prensa de contenidos emitidos por los grupos que no forman parte del gobierno, se analizó si las formaciones de la oposición hacen uso de herramientas como notas de prensa para trasladar su mensaje en unas condiciones similares a las de los partidos del gobierno. Para ello, se visitaron las webs de los aproximadamente 375 grupos municipales de la oposición que existen en las 145 mayores poblaciones de España. Los datos obtenidos indican que en 92 municipios al menos uno de los grupos políticos ajenos al ejecutivo sí ha realizado actividades comunicativas centradas en el ámbito local a través de notas de prensa que ha tenido que canalizar a través de su web como grupo municipal (en la mayoría de los casos ni siquiera presentadas con un link en la página de la institución). Es decir, que en el $63,4 \%$ de los ayuntamientos objeto de análisis sí existen comunicaciones que podrían haber sido recogidas en la página institucional si se aplicase el mismo criterio que se toma para los grupos políticos que forman gobierno.

\section{Conclusiones}

Las salas de prensa on line de los ayuntamientos españoles se conforman desde el punto de vista formal como departamentos institucionales con una imagen y un diseño web que responden a las características de los gabinetes del primer sector. Sin embargo, la dinámica de los mismos cruza en varias ocasiones los límites de la administración pública no solo por la ausencia de espacio propio e información sobre los grupos de la oposición (que, evidentemente, también forman parte del ayuntamiento $\mathrm{y}$, por lo tanto, debieran tener su espacio proporcional en la comunicación institucional), sino también por las características de la información y la comunicación realizada. Hemos establecido diferentes parámetros que nos permitieran identificar esa desviación (sobreexposición del alcalde en la información emitida por la institución, la referencia a contenidos puramente políticos de carácter supramunicipal, la utilización de medios públicos como altavoces de reivindicaciones ante administraciones 
de otro color político, la presencia de notas de prensa emitidas por otras instituciones jerárquicamente superiores, la combinación de declaraciones institucionales y políticas con intención de réplica a la oposición y los reproches a gobiernos anteriores) y constatamos que los órganos de comunicación de los ayuntamientos priorizan en general los intereses del tercer sector y, en consecuencia, prestan menos atención a los intereses de los ciudadanos. Del mismo modo, observamos a lo largo del análisis tendencias similares en todos los grupos municipales de los ayuntamientos españoles.

Finalmente, una de las piezas fundamentales para la democracia y de las ventajas de la red, la comunicación bidireccional no es explotada en estas salas de forma sistemática.

Por lo tanto, la comunicación en los ayuntamientos españoles se sitúa en la línea entre las características e intereses de los partidos políticos y los de la administración pública que no siempre coinciden y necesitan en muchas ocasiones de una separación que no se registra ni desde el punto de vista normativo ni de la dinámica de los mismos y puede perjudicar a la comunicación democrática entre la administración local y el ciudadano.

\section{Referencias bibliográficas}

ASOCIACIÓN DE DIRECTIVOS DE COMUNICACIÓN (2012): Anuario de comunicación. Madrid, Instituto Nacional de Administración Pública.

BARTOLOMÉ CASTRO, Manuel (2012): "La investigación sobre la comunicación de los partidos políticos. Un análisis del estado de la cuestión”, en PEÑA JIMÉNEZ, Palma (et al.): Comunicación institucional y política. Madrid, Fragua.

COSCULLUELA MONTANER, Luis (1993): Manual de derecho administrativo. Madrid, Editorial Civitas.

\section{Berta GARCÍA OROSA}

Correo electrónico: bertago@gmail.com

Filiación profesional: Profesora titular.

\section{Pablo VÁZQUEZ SANDE}

Correo electrónico: blinho87@gmail.com

Filiación profesional: Investigador

Dirección postal: Facultad de Ciencias da Comunicación. Universidad de Santiago de Compostela. Avenida de Castelao s/n. 15782. Santiago de Compostela. 